\title{
Treatment Switch Guided by HIV-1 Genotyping in Brazil
}

\author{
Unaí Tupinambás ${ }^{1,4}$, Flávia Andrade Ribeiro, \\ Agdemir Aleixo $^{2}$ and Dirceu Greco ${ }^{1,2,3}$
}

\author{
${ }^{1}$ Graduate Course in Tropical Medicine; ${ }^{2}$ Immunology and Molecular \\ Biology Laboratory; ${ }^{3}$ School of Medicine, Federal University of Minas \\ Gerais; ${ }^{4}$ Secretary of Health,Belo Horizonte, MG, Brazil
}

\begin{abstract}
We assessed the performance of HIV-1 genotyping tests in rescue therapy. Patients were divided into two groups: group 1_(genotyped), included those switching to new antiretroviral drugs based on HIV-1 genotyping data, and group 2 (standard of care -SOC), comprised those in rescue therapy who had not used this test. This was an open and non-randomized study, with 74 patients, followed up for a mean period of 12 months, from February 2002 to May 2003. The groups differed in the duration of antiretroviral use, experience with diverse drug classes (non-nucleoside reverse transcriptase inhibitors and protease inhibitors) and viral load $<2.6 \log _{10}$ copies/mL at any time during treatment. In 23 patients (group 1), the switch in antiretroviral (ARV) regimen was based on genotyping data; this test was not used for 51 patients (group 2). Two $\mathrm{CD}_{4}^{+}$lymphocyte counts and viral load counts were made for each patient during the study. Data from the pharmacy where patients received antiretroviral agents, medical charts, and direct interviews with patients to assess compliance to treatment, were analyzed. In the genotyped group, the average drop in viral load was $2.8 \log _{10}$, compared with a $1.5 \log _{10}$ difference in group 2; the difference was significant in the first assessment performed six months after switching $(p=0.001)$. Considering the patients with viral $\operatorname{load}_{2}<2.6 \log _{10}(400 \mathrm{copies} / \mathrm{mL})$ after switching, the patients in group 1 had a better performance in the first assessment (73.9\% versus 31.1\% in groups 1 and 2, respectively); this difference was significant $(p=0.001)$. In multivariate analysis, the variables associated with a greater drop in viral load in the first assessment were the patients whose switching was based on genotyping (group 1), those with a past history of viral $\operatorname{load}<2.6 \log _{10}$ and correct use of antiretroviral agents. In conclusion, the genotyping test and adherence were found to be independent factors for success in the management of patients who failed treatment.
\end{abstract}

Key Words: HIV-1, genotyping, antiretroviral resistance testing.

As of mid-1991, the National STD/AIDS Program of the Ministry of Health-Brazil (PNDST/AIDS-MS) adopted a policy to ensure free access to antiretroviral therapy (ARV) for patients with AIDS. In 2004, approximately 130,000 patients received this treatment. This policy has caused considerable impact on the HIV/AIDS epidemic, reducing morbidity and mortality [1]; however, roughly $50 \%$ of patients who initiate ARV have some type of therapeutic failure six months later [2]. This percentage is even higher in treatment-experienced patients who have changed therapy at least once [3]. Consequently, the effectiveness of this program is threatened by the emergence of resistant viral strains selected during treatment, which may be transmitted to other individuals. In 1993, Erice et al. reported zidovudine-resistant viral strain (T215Y) transmission, in which the patient presented a prolonged acute retroviral syndrome with a high viral load (VL) [4].

Genotyping tests were developed to help attenuate the impact of viral resistance. This test is able to detect mutations associated with phenotypic resistance of HIV to antiretrovirals.

Received on 19 November 2005; revised 30 March 2006.

Address for correspondence: Dr. Unaí Tupinambás. Rua Dona Cecília 81/ 301. ZIP Code: 30220-070. Belo Horizonte, MG Brazil. Phone: 55-31-3248-9822 fax:55-31-3281-7418.Email: unai@uai.com.br

The Brazilian Journal of Infectious Diseases 2006;10(2):82-88. (C) 2006 by The Brazilian Journal of Infectious Diseases and Contexto Publishing. All rights reserved.
The test is performed on virions, whose RNA is amplified by polymerase chain reaction (PCR) and sequenced in automated equipment. The viral amino acid sequence is compared with the standard wild virus sequence to identify mutations.

Several clinical and molecular studies were developed in Europe and in the United States to validate the usefulness of HIV-1 genotyping. The main objective of these studies was to assess the impact of this new methodology on salvage therapy based on the mutations that were identified.

The VIRADAPT study was carried out in Europe [5], based on a randomized longitudinal cohort (during the first six months); later, it became an open study. After a six-month follow-up, the group of patients submitted to genotyping presented a higher reduction in viral load than that of the group who had no such test results. The percentage of individuals with viral loads below the detection limit $(<200$ copies $/ \mathrm{mL}$ ) was also higher than in the group that was not genotyped (32\% versus $14 \%$, respectively).

Other genotyping studies were conducted with the same purpose. Among others, the GART [6] and the NARVAL [7] studies demonstrated the usefulness of HIV genotyping, compared to phenotyping. The Argenta [8] and Havana [9] studies evaluated the effects of compliance and expert advice on HIV-1 genotyping.

Chaix et al. [10] demonstrated that the group of patients submitted to genotyping had costs similar to those of the group with no access to this test. The costs of performing genotyping were compensated by reduced expenses with 
antiretrovirals, mainly protease inhibitors (PI). The authors highlighted the advantage of rational use of this drug class, thereby decreasing its side effects.

However, the use of viral resistance tests in clinical practice is still controversial. The decision to introduce a new methodology in routine medical care should be based on strong evidence. Though the conclusions of all clinical studies were based on laboratory-related events, translating these results into significant clinical gains is a great challenge. Furthermore, the viral resistance assay is a relatively complex laboratory test, and its inclusion in Public Health Services needs better evaluation.

Consequently, based on an operational study, the PNSTD/ AIDS-MS decided to implement a national network of laboratories that are able to perform genotyping tests (National Genotyping Network - RENAGENO). This network has been operative since February 2002. In this context, the Gerais Project (Group of Studies on Antiretroviral Resistance) was established, and its main objective was to acquire information necessary to assess the efficacy and feasibility of implementing this new technology in the Public Health System (SUS). This Project was implemented in the Reference Center on Infectious and Parasitic Diseases, in an agreement between the Federal University of Minas Gerais and the City Administration of Belo Horizonte (CTR/DIP). These services provide $\mathrm{CD}_{4}{ }^{+} \mathrm{T}$-lymphocyte counts, HIV viral load and HIV-1 genotyping.

This research project and the Informed Consent form were approved by the Research Ethics Committee of the Federal University of Minas Gerais.

\section{Material and Methods}

This main objective of this study was to assess if the decision to change a regimen based on genotyping test had a positive effect on response, proven by reductions in viral load and improvement in $\mathrm{CD}_{4}^{+} \mathrm{T}$-lymphocyte counts. The inclusion criteria were:

1 - individuals older than 18 years;

2- HIV-1 positive and under regular antiretroviral treatment;

3- registered in the CTR/DIP pharmacy;

4- viral load $=5,000$ copies $/ \mathrm{mL}$, collected up to three months before genotyping, or before the ARV regimen switch in the group of patients who had not been submitted to the test; 6- Virological failure characterized according to the criteria set by the PNSTD/AIDS Consensus Group on Antiretroviral.

Treatment. Reduction of $<1 \log _{10}$ (or up to 10-fold the initial value) after six months of treatment with a potent ARV regimen; increase in $\mathrm{VL}>0.5 \log _{10}$ (or by three-fold the absolute value) based on nadir (lower VL presented by the patient); > $0.5 \log _{10}$ variations between the two VL results (or by threefold the previous value). This was an open and non-randomized study, conducted from February 2002 to July 2003.
Patients. All patients were recruited from the CTR/DIP. Group 1 (genotyped group) consisted of patients for whom HIV-1 genotyping was used as a basis to switch the ARV regimen. Since the genotyping test was available from February 2002, most patients of this group were recruited from then on and followed up for a minimum period of seven months. Two $\mathrm{CD}_{4}^{+}$ T-lymphocyte counts and viral loads were obtained. Group 2 (SOC) consisted of patients who did not use the genotype test as orientation to switch ARV. In this group, the patients were recruited prospectively (from February 2002) and retrospectively, as of 2000, through data collection in medical records. When data were retrospectively collected, the patients had to have been followed up for a minimum period of 12 months after switching. In group 2, at least two $\mathrm{CD}_{4}^{+} \mathrm{T}$ lymphocyte counts and viral loads were assessed during the period. HIV-1 genotyping was done for 16 patients of this group. The CTR/DIP service has a serum library, where plasma from patients from which viral load and $\mathrm{CD}_{4}{ }^{+} \mathrm{T}$-lymphocyte count data had been collected is stored at $-70^{\circ} \mathrm{C}$. The plasma analyzed was that submitted to viral load analysis near the time of switching (up to three months before the switch).

HIV-1 genotyping. Sequencing was performed using a previously-described method [11]. Briefly, RNA was extracted from $0.2 \mathrm{~mL}$ of plasma using the guanidinethiocyanate lysis reagent contained in the AMPLICOR HIV Monitor ${ }^{\circledR}$ Test Kit (Roche Diagnostic Systems, Branchburg New Jersey, USA). Reverse strand cDNA was generated from viral RNA, and a first round polymerase chain reaction (PCR) was performed using Superscript One-Step RT-PCR (Life Technologies, Rockville, Maryland, USA). A 1.3-kb product encompassing a protease gene and the first 300 residues of a RT gene was then amplified with nested PCR primers. Direct PCR (population-based) cycle sequencing was performed using AmpliTaq DNA FS polymerase and dRhodamine terminators (Applied Biosystems, Foster City, California, USA). Electropherograms were created and the sequences were assembled using the manufacturer's sequence analysis software.

Mutations. Mutations were defined as amino acid changes from the B-consensus. In agreement with the International AIDS Society-USA drug-resistance testing guidelines [12], primary protease inhibitor (PI) resistance mutations were defined as mutations at protease positions $30,46,48,50,82$ (but not V82I), 84 and 90; secondary PI resistance mutations were defined as mutations at protease positions 10, 20, 24, 32, $33,36,47,53,71,73,77$ and 88 . Nucleoside reverse transcriptase inhibitor (NRTI) resistance mutations were defined as mutations at reverse transcriptase (RT) positions $41,44,62$, $65,67,69,7074,75,77,115,116,118,151,184,210,215$ and 219. Non-nucleoside reverse transcriptase inhibitor (NNRTI) resistance mutations were defined as mutations at RT positions 100, 103, 106, 108, 181, 188, 190, 225, 230 and 236. 
Compliance assessment. Two non-excluding methods were used to assess compliance to treatment: 1) direct interview with patients or by examining the medical charts; 2) checking dispensing forms in the hospital pharmacy during the previous three months to assess the regularity of pharmacy visits to obtain antiretroviral agents. In the direct interviews, patients were classified as having good compliance to treatment if they had taken all doses in the past three days; otherwise they were classified as non-compliant (incorrect use). When there was no report of compliance in the medical records, or when it was not possible to carry out the interview, the only criterion applied was assessment of dispensing forms in the pharmacy.

Statistical analysis. The chi-square test $\left(\chi^{2}\right)$ was used to compare the two groups regarding the following variables: sex, history of undetectable viral load $\left(<2.6 \log _{10}\right)$, experience with NNRTI, regular use of ARV in the first and second assessments, viral load $<2.6 \log _{10}$ in both assessments. This test is used to compare independent groups for the percentage of occurrence of a certain event. In cases for which the expected values were less than 5, we used Fisher's exact test. The Student's t test was used for independent samples to compare the groups regarding the following variables: age, number of medication switches due to therapeutic failure, period of ARV use, period of PI use, nadir $\mathrm{CD}_{4}^{+} \mathrm{T}$-lymphocyte count, baseline viral load (before switching), date of $\mathrm{CD}_{4}^{+} \mathrm{T}$ lymphocyte count, date of viral load in the first and second assessments, and the difference between the viral load and $\mathrm{CD}_{4}^{+} \mathrm{T}$-lymphocyte counts observed in the first and second assessments in comparison to baseline.

The Student's t test was also used to assess the influence of several variables (group, sex, history of VL $<2.6 \log _{10}$, experience with NNRTI and correct use of $\mathrm{ARV}$ ) on $\mathrm{CD}_{4}^{+} \mathrm{T}$-lymphocyte counts and the first and second assessments of $\mathrm{VL}$.

The evaluation of $\mathrm{CD}_{4}^{+} \mathrm{T}$-lymphocyte counts and viral load progression during the follow-up period was performed by the Friedman test.

A multiple linear regression analysis was performed (more than one explanatory/regression variable), to determine the variables that affected $\mathrm{CD}_{4}^{+} \mathrm{T}$-lymphocyte counts and viral load. The significance level for all results was $<5 \%(\mathrm{p}<0.05)$.

\section{Results}

Seventy-four patients were included in the study. In group 1 (genotyping), 50 patients were analyzed with the genotyping test, 23 of which met the inclusion criteria. In group 2 (SOC), 51 patients were selected. In this group, genotyping tests were made on 16 serum aliquots stored in the laboratory of the service at $-70^{\circ} \mathrm{C}$.

Most patients were male ( $87 \%$ ), and significant differences were observed in the two groups. The mean age in group 1 (genotyped) was significantly greater. Significantly more patients $(64 \%)$ in the genotyped group attained a viral load < $2.6 \log _{10}$ (<400 copies/mL), at some time during treatment, than in the not-genotyped group (37\%). The not-genotyped group also had a significantly higher percentage of patients with no previous experience with NNRTI (nevirapine, efavirenz or delavirdine).

In group 1 (genotyped), longer exposure time to ARV and protease inhibitors (PI) was identified. The two groups had similar numbers of switches due to drug failure, nadir $\mathrm{CD}_{4}^{+} \mathrm{T}$ lymphocytes, baseline $\mathrm{CD}_{4}^{+} \mathrm{T}$-lymphocytes and VLs (Table 1).

The two groups had similar rates of correct use of ARV (based on the medical records or patient interviews) in the first and second assessments. Significant differences were found between the two groups for the following variables: mean duration of treatment up to the $\mathrm{CD}_{4}^{+} \mathrm{T}$-lymphocyte count in the first assessment, VL value and its variation in the first assessment, and the differences in the $\mathrm{CD}_{4}^{+} \mathrm{T}$-lymphocyte counts in the second assessment when compared to baseline. In the first assessment after switching (six months), the proportion of patients achieving a VL $<2.6 \log _{10}$ was significantly greater in group 1 (genotyped). In the second assessment (12 months), the difference between the two groups was not significant (Table 2).

The multivariate analysis included the variables that were significant in the univariate model. The variable compliance was used in the first assessment (six months) in two models. In the first, the criterion to assess compliance was based on information from dispensing forms in the pharmacy (a less strict criterion to assess compliance, $n=74)$; in the second model, only patient interviews or medical records were considered (a more strict criterion to assess compliance, $n=46$ ). In the first model, the following variables had some influence on VL in the first assessment (six months): patient group, past history of VL $<2.6 \log _{10}$, and compliance. A higher viral load was positively associated with group 2 (no genotyping), with incorrect use of ARV and with patients with no past history of $\mathrm{VL}<2.6 \log _{10}$ (Table 3$)$. In the second model, the significant variables associated with higher VL were not genotyped and non-compliance with treatment (Table 4).

An expected drop in VL occurred only in patients compliant with ARV; among these patients, it was greater in the genotyped group (Figure 1).

In the univariate analysis, only the variable correct use of ARV was directly related to increased $\mathrm{CD}_{4}^{+} \mathrm{T}$-lymphocyte counts. In the multivariate analysis, none of the variables were significantly related to higher $\mathrm{CD}_{4}^{+} \mathrm{T}$-lymphocyte counts.

Resistance profile analysis. In the phylogenetic analysis of the pol gene (reverse transcriptase or protease), most viral strains were of the B subtype. The mutations K65R and INS69 were not observed, and only one sample had the mutation Q151M. Group 2 patients (SOC) more frequently had wild virus (Table 5). 
Table 1. Baseline characteristics of group 1 (genotyped) and group 2 (SOC) patients

\begin{tabular}{lccc}
\hline Characteristic & $\begin{array}{c}\text { Group1 n=23 } \\
\text { (genotyped) }\end{array}$ & $\begin{array}{c}\text { Grupo2 n=51 } \\
\text { (SOC) }\end{array}$ & Pvalue \\
\hline Mean age (years) & 47.2 & 41.8 & $=0.03$ \\
Male $(\%)$ & 87 & 80.4 & $=0.74$ \\
Years of ARV exposure (median) & 4.5 & 2.8 & $<0.001$ \\
NNRTI naive (\%) & 30.4 & 68.6 & $=0.002$ \\
Months of PI exposure (median) & 34.8 & 21.1 & 0.01 \\
Number of switches due to drug failure (median) & 1.7 & 1.4 & 0.08 \\
History of HIV-RNA<400 copies $/ \mathrm{mL}(\%)$ & 63.6 & 37.3 & $=0.04$ \\
Nadir de $\mathrm{CD}_{4}^{+}\left(\right.$median) $/ \mathrm{mm}^{3}$ & 129 & 136 & 0.82 \\
Median $\mathrm{CD}_{4}^{+}$cell counts baseline $\left(/ \mathrm{mm}^{3}\right)$ & 236 & 63 & 0.43 \\
Median $\mathrm{HIV}^{3}$-RNA at baseline $\left(\log _{10}\right)$ & 4.5 & 4.5 & 0.69 \\
\hline
\end{tabular}

NNRTI = non-nucleoside reverse transcriptase inhibitor. $\mathrm{PI}=$ protease inhibitors .

Table 2. Variation in virus load (VL) value, $\mathrm{CD}_{4}{ }^{+} \mathrm{T}$-lymphocyte counts and adherence to antiretroviral therapy (ARVT) in the second assessment in relation to baseline in group 1 (genotyped) and group 2 (SOC)

\begin{tabular}{|c|c|c|c|c|}
\hline & Characteristic & $\begin{array}{c}\text { Group 1, n=23 } \\
\text { (genotyped) }\end{array}$ & $\begin{array}{c}\text { Group 2, n=51 } \\
\text { (SOC) }\end{array}$ & Pvalue \\
\hline \multirow[t]{4}{*}{ Correct use of ARV } & Patient adherence (\%) & & & \\
\hline & $1^{\text {st }}$ assessment & 95.7 & 87 & $=0.61$ \\
\hline & Patient adherence (\%) & & & \\
\hline & $2^{\text {nd }}$ assessment & 82.6 & 87 & 1.0 \\
\hline \multirow{2}{*}{$\begin{array}{l}\text { Mean duration of treatment } \\
\text { up to } \mathrm{CD}_{4}^{+} \mathrm{T} \text {-lymphocyte count } \\
\text { in the first assessment after } \\
\text { switching (day) }\end{array}$} & $1^{\text {st }}$ assessment & 212 & 157 & 0.005 \\
\hline & $2^{\text {nd }}$ assessment & 356 & 336 & 0.35 \\
\hline \multirow{2}{*}{$\begin{array}{l}\text { Mean duration of treatment } \\
\text { up to viral load count after } \\
\text { switching (day) }\end{array}$} & $1^{\text {st }}$ assessment & 209 & 171 & 0.06 \\
\hline & $2^{\text {nd }}$ assessment & 350 & 340 & 0.71 \\
\hline \multirow{2}{*}{ Median $\mathrm{CD}_{4}^{+}$cell counts $\left(/ \mathrm{mm}^{3}\right)$} & $1^{\text {st }}$ assessment & 304 & 302 & 0.97 \\
\hline & $2^{\text {nd }}$ assessment & 349 & 324 & 0.61 \\
\hline \multirow{2}{*}{ Viral load $\left(\log _{10}\right)$ median } & $1^{\text {st }}$ assessment & 1.7 & 3.0 & 0.005 \\
\hline & $2^{\text {nd }}$ assessment & 2.2 & 2.7 & 0.29 \\
\hline Median increase in $\mathrm{CD}_{4}^{+}$ & $1^{\text {st }}$ assessment & 69 & 42 & 0.36 \\
\hline T-lymphocyte count $\left(/ \mathrm{mm}^{3}\right)$ & $2^{\text {nd }}$ assessment & 108 & 61 & 0.04 \\
\hline Median decrease in viral & $1^{\text {st }}$ assessment & -2.8 & -1.5 & 0.004 \\
\hline load count $\left(\log _{10}\right)$ & $2^{\text {nd }}$ assessment & .2 .4 & -1.8 & 0.24 \\
\hline
\end{tabular}

Table 3. Results of multiple linear regression analysis at the first assessment, in patients with a less strict criterion to assess compliance $(\mathrm{n}=74)$

\begin{tabular}{lcc}
\hline Variable & Coefficient & Pvalue \\
\hline Patient group 2 (SOC) & 1.35 & 0.001 \\
Non-adherence & 2.43 & 0.005 \\
History of viral load $<2.6 \log _{10}$ & 0.72 & 0.05 \\
Constant & -2.6 & \\
\hline
\end{tabular}

$\mathrm{R}^{2}=0.326$.
Table 4. Results of multiple linear regression analysis at the first assessment, in patients with a more strict criterion to assess compliance $(\mathrm{n}=46)$

\begin{tabular}{lcc}
\hline Variable & Coefficient & Pvalue \\
\hline Non-adherence & 2.88 & 0.002 \\
Patient group 2 (SOC) & 1.02 & 0.031 \\
Constant & -2.49 & \\
\hline
\end{tabular}

$\mathrm{R}^{2}=0.307$ 
Table 5. Resistance profile analysis

\begin{tabular}{lcc}
\hline Variables & Group 1 (n=23) & Group 2 (SOC) n=16 \\
\hline HIV-1 subtype (\%) & $\mathrm{B}(72.7 \%)$ & $\mathrm{B}(75 \%)$ \\
& $\mathrm{F}(18.2 \%)$ & $\mathrm{F}(6.3 \%)$ \\
& Recombinant $(9.1 \%)$ & $31.3 \%$ \\
Wild virus (according to NRTI) (\%) & $9.1 \%$ & $62.5 \%$ \\
Wild virus (according to NNRTI) $(\%)$ & $31.8 \%$ & $25 \%$ \\
Wild virus (according to PI) (\%) & $9.1 \%$ & $75 \%$ \\
Presence of primary PI resistance mutations & $86.4 \%$ & $6.25 \%(1$ case with Q151M) \\
Presence of INS69 or K65R or Q151M & 0 & Recomint $(18.7 \%)$
\end{tabular}

NRTI = nucleoside reverse transcriptase inhibitor. NNRTI $=$ non-nucleoside reverse transcriptase inhibitor. PI $=$ protease inhibitor.

Figure 1. Mean reduction in VL comparing compliant and non-compliant patients $(\mathrm{n}=46)$.

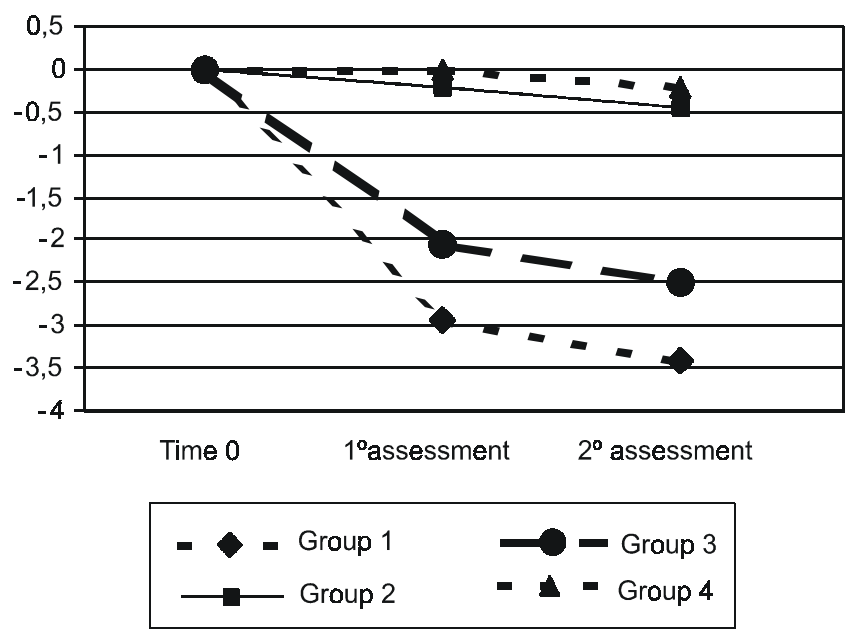

When comparing the genotyping results for 16 plasma samples from group 2 patients, there were fewer mutations related to ARV when the drug regimen was switched. Even so, this group received less active drugs than the group undergoing treatment directed by genotyping (Figure 2).

\section{Discussion}

This is the first study conducted in Brazil assessing HIV1 genotyping in salvage therapy, and it may be a starting point for others. We used a convenient sample, with no randomization. All patients enrolled were registered in the CTR/ DIP and regularly followed-up. This type of sampling has the limitation of not necessarily being representative, since it is impossible to assure that the patients enrolled in the study are similar to the rest of the general population.

There have been several reports of the benefits of HIV-1 genotyping in salvage therapy of patients who have had drug failure. Considering that the test was already available
Figure 2. Number of active drugs in with group.

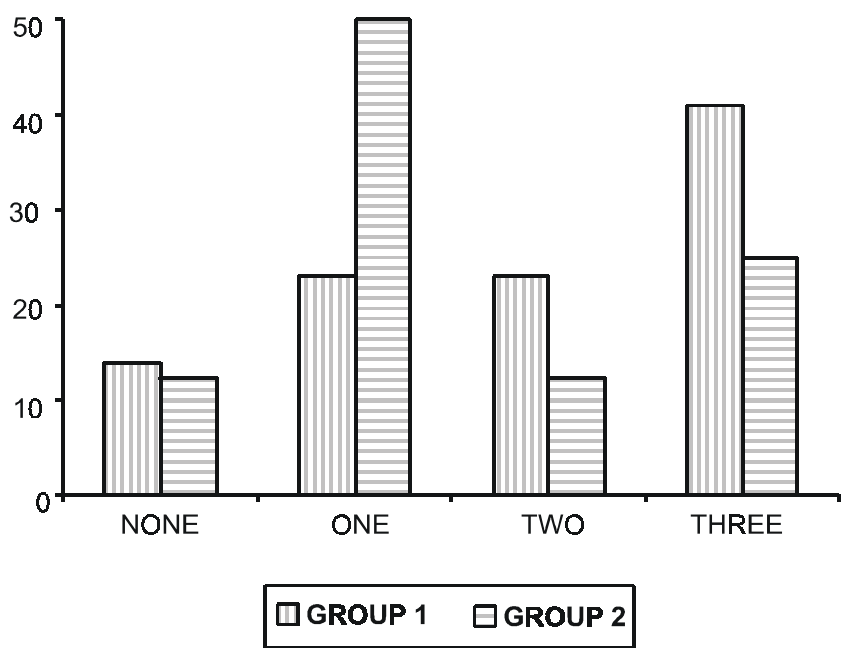

in public services, randomizing patients into two groups (group 1 - genotyping, group 2 - SOC) would not have been ethical. In order to avoid this problem, group 2 patients were selected in a historical cohort from 2000, by means of active data collection in medical records and ARV request forms received by the service pharmacy. Switching due to virological failure from this date and being regularly followedup were basic conditions to be enrolled in the study, and only patients seen by physicians who ordered genotyping tests were included. Consequently, it was assured that the patients of these groups were seen by the same team of physicians, avoiding follow-up by professionals with diverse experiences, removing confounding variables. This medical team was comprised of qualified and skilled professionals who comply with the standards on the use of antiretrovirals set by the Brazilian Ministry of Health. Moreover, the CTR/ DIP has a committee that only releases medication if the regimen complies with the standards of the National STD/ AIDS Program. 
Although the criteria for therapeutic failure established by the Ministry of Health (2003) were not modified during the study, some medications were not available at the beginning of 2000 (for instance, lopinavir/r), which could be another limitation contributing to the different results in the groups. In addition, new concepts on salvage therapy, and ARV crossresistance against various drugs, may have influenced the diverse therapeutic options during this period.

Genotypic-resistance testing was beneficial for making decisions about changes in treatment. We found a significantly better virological outcome (percentage of patients with plasma viral load (pVL) $<400$ copies $/ \mathrm{mL}$ and a decrease in $\mathrm{pVL}$ from baseline) at the six-month follow-up in patients in the genotyped group, compared with those who were not genotyped (SOC). Multivariate analysis confirmed genotype information as an independent predictor of virological success. Nevertheless, the advantage of genotyping information was lost after 12 months. These findings were similar to results from previous randomized studies [5-9], indicating that resistance testing helps to choose more effective regimens in patients failing previous antiretroviral regimens. Although group 2 patients had fewer mutations and viral samples with no mutations (wild type virus, Table 5), this group received less active drugs (Figure 2), thus emphasizing the importance of genotyping in salvage therapy. These data are similar to those published by Baxter et al. [6]. In order to assess the impact of the correct use of ARV and drop in viral load, some studies have used protease inhibitor serum levels [15], whereas we examined patient and/or assistant physician compliance (more strict compliance assessment). The reduction in VL was greater in the group that reported good compliance, regardless of whether the patients had HIV-1 genotyping done (Figure 1).

As in other studies [5,6], the increased $\mathrm{CD}_{4}^{+} \mathrm{T}$-lymphocyte counts did not differ between the groups. This may be explained by the fact that $\mathrm{CD}_{4}^{+}$counts increase slower than the reduction in viral load, thus requiring more time to appear. The increased $\mathrm{CD}_{4}{ }^{+}$count was related to compliance, regardless of the group (genotyped or not), as also found by Cingolani et al. [8].

Although we did not aim to assess compliance to ARV, three mechanisms were used to that allow such an evaluation: regularity of pharmacy utilization to obtain ARV agents during the previous three months, information in the medical records about compliance, and patient interviews. In a recent study carried out by our team concerning compliance to ARV [15], there were no significant differences between these criteria: assessing dispensing forms in the pharmacy, interviews with patients or filling out a questionnaire on the use of $\mathrm{ARV}$, making all of them valid.

The accuracy of these methods to measure different levels of compliance is unknown. In many studies, levels of compliance are divided as follows: $<80 \%, 80 \%$ to $90 \%, 95 \%$ to $99 \%$ and $100 \%$ use of prescribed doses. Use of above $80 \%$ of prescribed doses has been associated with better results, both regarding $\mathrm{VL}$ and $\mathrm{CD}_{4}^{+} \mathrm{T}$-lymphocyte counts. When compliance increased, the test results were better $[16,17]$, though this type of evaluation was not made in our study. In our investigation, good compliance was considered as having taken all doses in the previous three days ( $100 \%$ compliance). As mentioned above, patients benefit from compliance above $80 \%$. This approach is similar to that adopted by Cingolani et al. in the Argenta study [8]. However, there was a trend towards $<100 \%$ compliance and virological failure in both group 1 (genotyped) and group 2 (SOC) patients (Figure 1).

Based on the pharmacy records, $100 \%$ of the patients had regular ARV dispensing during the study period. This demands a careful assessment, and another regression model was used to analyze this variable as a function of viral load.

The therapeutic response assessed by VL variation stood out in this study. The patients had been using ARV for a long period, on average, 4.5 and 2.8 years for groups 1 and 2, respectively. Many patients had been on ARV from the time of sequential therapy with two drugs to the highly potent antiretroviral therapy era (HAART - Highly Active Antiretroviral Therapy). There was a significant reduction in viral load: $-2.8 \log _{10}$ and -1.5 in groups 1 and 2 , respectively. These results are better than those of other clinical trials concerning HIV-1 genotyping [18]. The salvage therapy performance in this population could be explained by the rate of correct ARV use, observed in over $80 \%$ of patients in both groups. In the Cingolani study [8], this rate was only $57 \%$.

\section{Conclusions}

HIV-1 genotyping has been demonstrated to be feasible in public healthcare services, and its efficacy in salvage therapy of patients was confirmed in our study, at least in the first assessment year. RENAGENO should take advantage of its infrastructure and suggest a multicenter study throughout Brazil.

The criteria for drug failure and the best moment to switch $\mathrm{ARV}$ should be rethought. If the main objective is virological control, with ARV switching based on this parameter, within a short period the therapeutic armamentarium available will become depleted. On the other hand, if increased $\mathrm{CD}_{4}{ }^{+} \mathrm{T}$ lymphocyte counts are the objective, regardless of virological failure, there will be a risk of facilitating the emergence of viral strains resistant to all drugs currently available. In order to clarify these issues, it will be necessary to follow patients for longer periods and to analyze the events of interest, that is, laboratory data, clinical picture and the quality of life of patients. Such follow-up may be established by RENAGENO. It was demonstrated that the correct use of ARV is an important factor, both for virological response and for immunological 
recovery, thus stressing the need for better compliance to prescriptions. The following healthcare actions could enhance compliance: establishing groups of patients to discuss and provide information, reducing waiting time for visits, regular follow-up visits and active search for patients who do not come to visits, home care or home visits, and paying for transportation expenses. In addition, there should be a search for simpler therapeutic regimens, such as combining drugs in one tablet that could be given less frequently.

\section{Acknowledgements}

The authors thank Denise Arakaki and Suelene Mamede de Oliveira of the Programa Nacional de DST/AIDS-Brasil and themembers of the National Genotyping Network: Amílcar Tanuri, Celso Ramos, Érico Aruda, Éster Sabino, José Luiz de Andrade Neto, Ricardo Diaz, Rodrigo Brindeiro.

\section{References}

1. Marins J.R., Jamal L.F., Chen S.Y., et al. Dramatic improvement in survival among adult Brazilian Aids patients. AIDS 2003; $17: 1675-82$.

2. Hoetelmans Richard. Pharmacological exposure and development of drug resistance in HIV. Antiviral Therapy 2001;6(Suppl.2):37-47.

3. Wit F.W., van Leewen R., et al. Outcome and predictors of failure of highly active antiretroviral therapy: one-year followup of a cohort of human immunodeficiency type- 1 infected persons. Journal of Infectious Diseases 1999;179:790-8.

4. Erice A., Mayers D., Strike D., et al. Primary Infection with Zidovudine-Resistant Human Immunodeficiency Virus Type 1. N Eng J Med 1993; 328:1163-5.

5. Durant J., Clevenbergh P., Halfon P., et al. Drug-resistance genotyping in HIV-1 therapy: the VIRADAPT randomized controlled trial. The Lancet 1999;353:2195-9.

6. Baxter J.D., Mayers D.L., Wentworth D.N., et al. A randomized study of antiretroviral management based on plasma genotypic antiretroviral resistance testing in patients failing therapy. AIDS 2000;14:F83-F93.
7. Meynard J.L., Vray M., Morand-Joubert L., et al. Phenotypic or genotypic resistance testing for choosing antiretroviral therapy after treatment failure: a randomized trial. AIDS 2002; $16: 727-36$.

8. Cingolani A., Antinori A., Rizzo M.G., et al. Usefulness of monitoring HIV drug resistance and adherence in individuals failing highly active antiretroviral therapy: a randomized study (ARGENTA). AIDS 2002;16:369-79.

9. Tural C., Ruiz L., Holtzer C., et al. Clinical utility of HIV-1 genotyping and expert advice: the Havana trial. AIDS 2002;16:209-18.

10. Chaix C., Grenier-Sennelier C., Clevenbergh P., et al. Economic evaluation of drug resistence genotyping for the adaptation of treatment in HIV infected patients in the VIRADAPT study. J Acquir Imm Defic Synd 2000;24;227-31.

11. Shafer R.W., Hertogs K., Zolopa A.R., et al. High degree of interlaboratory reproducibility of human immunodeficiency virus type 1 protease and reverse transcriptase sequencing of plasma samples from heavily treated patients. J Clin Microbiol 2001;39:1529-52.

12. Dáquila R.T., Schapiro J.M., Brun-Vezinte F., et al. Drug resistance mutations in HIV-1. Top HIV Med 2003;11:92-96

13. Pereira MG. Epidemiologia - Teoria e Prática. Rio de Janeiro: Editora Guanabara Koogan S.A.,583p.,1995.

14. Durant J., Clevengberth P., Garraffo R., et al. Importance of protease inhibitor plasma levels in HIV infected patients treated with genotyping-guided therapy: pharmacological data from the Viradapt Study. AIDS 2000;14:1333-9.

15. Lignani J.R. Avaliação da aderência aos anti-retrovirais em amostra de pacientes acompanhados no Centro de Treinamento e Referência em Doenças Infecciosas e Parasitárias, Belo Horizonte-MG. Dissertação de Mestrado, 103 p., 2000.

16. Haubrich R.H., Little S.J., Currier J.S., et al. The value of patientreported adherence to antiretroviral therapy in predicting virologic and immunologic response. California Collaborative Treatment Group. AIDS 1999; 13:S189-S204.

17. Hecht F.M., Colfax G., Swanson M., et al. Adherence and effectiveness of protease inhibitors in clinical practice. In: Fifth Conference on retrovirus and Opportunistic Infections. Chicago, February 1998. \{Abstract 151\}.

18. Hirsch M.S., Brun-Vézint F., Clotet B., et al. Antiretroviral Drug Resistance Testing in Adults Infected with Human Immunodeficiency Virus Type 1: 2003 Recommendations of an International AIDS Society-USA Panel. CID 37:113-28. 